\title{
From network depolymerization to stress corrosion cracking in sodium-borosilicate glasses: Effect of the chemical composition
}

\author{
Marina Barlet ${ }^{\mathrm{a}}$, Jean-Marc Delaye ${ }^{\mathrm{b}}$, Bruno Boizot ${ }^{\mathrm{c}}$, Daniel Bonamy ${ }^{\mathrm{a}}$, Richard Caraballo ${ }^{\mathrm{b}}$, \\ Sylvain Peuget ${ }^{\mathrm{b}}$, Cindy L. Rountree ${ }^{\mathrm{a}, *}$
}

a SPEC, CEA, CNRS, Université Paris-Saclay, CEA Saclay, 91191 Gif-sur-Yvette, France

b CEA, DEN, DTCD, SECM, LMPA Marcoule, France

c LSI, Ecole Polytechnique, CEA, CNRS, Université Paris-Saclay, 91128 Palaiseau, France

\section{A R T I C L E I N F O}

\section{Article history:}

Received 20 May 2016

Received in revised form 7 July 2016

Accepted 14 July 2016

Available online 12 August 2016

\section{Keywords:}

Stress corrosion cracking

Sodium borosilicate glass

Fracture

\begin{abstract}
A B S T R A C T
The study herein examines how chemical composition impacts sub-critical stress corrosion cracking (SCC) in sodium borosilicate glasses. The crack speed versus stress intensity factor ( $v$ vs. $\left.K_{I}\right)$ curves were obtained for seven ternary $\mathrm{SiO}_{2}-\mathrm{Na}_{2} \mathrm{O}-\mathrm{B}_{2} \mathrm{O}_{3}$ (SBN) glasses of selected chemical compositions. $\mathrm{Na}_{2} \mathrm{O}$ plays an interesting role in the $\mathrm{SCC}$ behavior. First, increasing the $\mathrm{Na}_{2} \mathrm{O}$ concentration yields an increase in the environmental limit $\left(K_{e}\right)$. Second, increasing the $\mathrm{Na}_{2} \mathrm{O}$ concentration affects how fast SCC occurs as $K_{I}$ increases (i.e. the slope in region I SCC). This second effect is highly nonlinear: it is insignificant for $\mathrm{Na}_{2} \mathrm{O}<20 \%$ but it becomes increasingly important above $20 \%$, when sodium acts as a network modifier. Raman spectroscopy and Molecular Dynamics (MD) simulations aid in revealing the structural variations which arise from increasing concentrations of $\mathrm{Na}_{2} \mathrm{O} . \mathrm{Na}_{2} \mathrm{O}$ causes the relative proportions of the different chemical bonds accessible in SBN glasses to vary. For this series of glasses, the $\mathrm{Si}-\mathrm{O}-\mathrm{Si}$ bond does not dominate the SCC properties. SCC variations originate in the mesoscale structure where sodium ions act as network modifiers on both the silica and borate units, thus yielding a partial depolymerization (i.e. a decrease in the reticulation level) of the network. This second effect reveals itself to be the one responsible for the SCC chemical dependency. Poisson's ratio increases approximately linearly with increasing $\mathrm{Na}_{2} \mathrm{O}$ concentration, and thus, it is also not simply proportional to the slope in region I SCC. Partial depolymerization of the glass provides a novel prospective on the controlling factors in the sub-critical crack growth.
\end{abstract}

(c) 2016 Elsevier B.V. All rights reserved.

\section{Introduction}

Stress-corrosion cracking is a phenomenon by which water (or other environmental factors) aids in the slow propagation of pre-cracks/flaws in materials. This slow propagation gains speed untimely leading to the overall failure of the material. This is one of the reasons why glass walkways (e.g. London Bridge, Grand Canyon, Yuntaishan Sky Walkway, Eiffel Tower...) have sacrificial protective glass panels which are removed when flaws are visible. In the absence of a corrosive environment, the stress intensity factor (i.e. stress felt by the crack front, $K_{I}$ ) must exceed the material's fracture toughness $\left(K_{c}\right)$ for a crack front to propagate [1-3]. Yet, within a corrosive environment, water molecules attack the stretched network at the crack tip causing sub-critical crack propagation (i.e. $K_{I}<K_{c}$ ).

In general, three regions exist in the sub-critical cracking domain (Fig. 1). In region I, the crack front velocity, $v$, depends on the chemical reactions rates at the crack tip. In region II, the crack front velocity depends on the time for the water to reach the crack front. In region III, the crack front moves too fast for water to reach the crack front $[1,4]$.

\footnotetext{
* Corresponding author.

E-mail address: cindy.rountree@cea.fr (C.L. Rountree).
}

Occasionally, a fourth region, region 0 or the environmental limit $\left(K_{e}\right)$, exists. $K_{e}$ defines a threshold limit below which a crack front will not propagate.

Efforts to relate the SCC $v$ as a function of $K_{I}$ to the glass's chemical composition remain rather rudimentary as glasses are far too complex for a comprehensive analysis based on a rather small number of samples [1-5]. In these studies [1-5], a continuing hypotheses persists that the rupture of the $\mathrm{Si}-\mathrm{O}-\mathrm{Si}$ bond and/or the reaction rate theory control the SCC dynamics in region I [1-3]. This paper puts this hypothesis to test in $\mathrm{SiO}_{2}-\mathrm{Na}_{2} \mathrm{O}-\mathrm{B}_{2} \mathrm{O}_{3}$ ( $\mathrm{SBN}$ ) glasses. Moreover, it will overturn this hypothesis for the SBN series and shows that the depolymerization (the amount of reticulation in the glass network) controls the sub-critical crack propagation.

This paper should be seen as the third in a series, the first two being Barlet et al. 2013 [6] and 2015 [7]. Ternary SBN glasses provide a simple model glass to examine the importance of a glass's chemical composition on its mechanical response in region 0 and I. Glasses herein contain two network formers $\left(\mathrm{SiO}_{2}\right.$ and $\left.\mathrm{B}_{2} \mathrm{O}_{3}\right)$ and one network modifier $\left(\mathrm{Na}_{2} \mathrm{O}\right)$. These three components represent the major components for many industrial glasses; yet, little is known about how the chemical composition alters the stress corrosion cracking (SCC) properties. This paper examines $v$ versus $K_{I}$ curves for regions 0 and I for seven ternary 


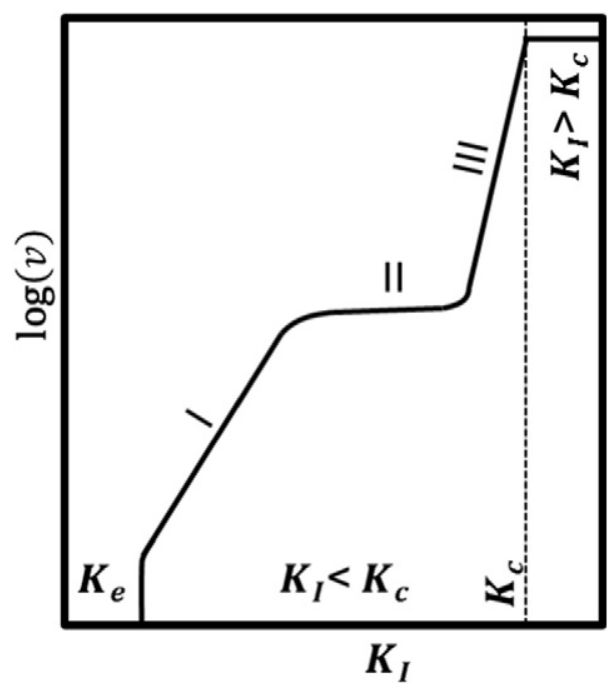

Fig. 1. Sketch of the 3 regions of sub-critical cracking commonly associated with stress corrosion cracking. In some materials, a region exists where the stresses at the crack tip are not sufficient for water to react with the crack tip, yielding an environmental limit, $K_{e}[1]$.

$\mathrm{SiO}_{2}-\mathrm{Na}_{2} \mathrm{O}-\mathrm{B}_{2} \mathrm{O}_{3}$ (SBN) glasses. Herein, $K_{e}$ clearly shifts to higher environmental limits when $\mathrm{Na}_{2} \mathrm{O}$ increases. On the other hand, SBN glasses display an increasing susceptibility to water as $\mathrm{Na}_{2} \mathrm{O}$ increases [8] as evidenced by an increasing slope in region $\mathrm{I}$. These results highlight $\mathrm{Na}_{2} \mathrm{O}$ role on the mechanical behavior of glasses. Furthermore, they depend on $\mathrm{Na}_{2} \mathrm{O}$ 's role in the glass: network modifier or network charge compensator. Results herein reveal the depolymerization of the glass provides an indication of the stress corrosion cracking behavior in region I. These findings provide a new prospective on the controlling factors in sub-critical crack growth.

\section{Methods}

Barlet et al. 2013 [6] and 2015 [7] directly concern the series of SBN glasses presented herein and should be regarded as precursors to this paper. Most experimental and numerical protocols invoked in this study have been extensively tested and reported elsewhere. Thus, this section briefly reviews experimental and numerical protocols and references detailed works for further readings. The first Subsection 2.1 details the chemical composition of the 7 SBN glasses and recalls the standard way to characterize them. Subsection 2.2 describes fracture tests used to characterize the stress corrosion cracking (SCC) behavior. Subsection 2.3 details the spectroscopy tests used to analyze and characterize the structure of the glass. Subsection 2.4 recalls methods to acquire density, Poisson's ratio, and the Young's modulus. The last Subsection 2.5, details the numerical MD simulations which provide the structural organization of the atoms in the 7 SBN glasses.

\subsection{Glass chemical composition}

Glass fabrication invokes the same procedure as previously reported by the coauthors [6,7]. Table 3 recalls the target chemical composition of each glass [6]. A third party (PrimeVerre) verifies the glass chemical compositions via SEM-EDS (Environmental Scanning Electronic Microscope coupled with an Energy Dispersive Spectrometer) and/or ICPAES (Inductively Coupled Plasma Atomic Emission Spectroscopy). SEM-EDS results revealed small amounts of impurities, $<0.5 \%$. Results reported herein are from ICP-AES measurements and have an uncertainty of $10 \%$. Previous works by the co-authors examined and reported the chemical composition of the glasses along with their densities, glass structure, and hardness [6,7,9-11]. When possible, the same batch was used here as in the previous papers.
Table 1 recalls the measured ICP-AES, $K_{S B N}\left(\frac{\left[\mathrm{SiO}_{2}\right]}{\left[\mathrm{B}_{2} \mathrm{O}_{3}\right]}\right)$ where $[\cdot] \equiv \mathrm{mol} \%$ [6], $R_{S B N}\left(\frac{\left[\mathrm{Na}_{2} \mathrm{O}\right]}{\left[\mathrm{B}_{2} \mathrm{O}_{3}\right]}\right)$, and density $(\rho)$ presented in [6,7]. Sample classification herein concerns two $K_{S B N}$ groupings: $2.52 \pm 0.03$ (blue series) and $4.6 \pm$ 0.12 (red series). Grouping glasses via their $K_{S B N}$ value provides a constant $\mathrm{mol} \%$ ratio between $\left[\mathrm{SiO}_{2}\right]$ and $\left[\mathrm{B}_{2} \mathrm{O}_{3}\right]$. A secondary parameter aids in categorizing the glasses: $R_{S B N}=\frac{\left[\mathrm{Na}_{2} \mathrm{O}\right]}{\mathrm{B}_{2} \mathrm{O}_{3}}$. Authors invoke the $R_{S B N}$ and $K_{S B N}$ parameters as they aid in estimating elementary units $\left(\mathrm{BO}_{3}\right.$ planar units, $\mathrm{BO}_{4}$ tetrahedral, Metaborate units, pyroborate units, Silica tetrahedral with $i$ ( $i=1$ to 4 ) bridging oxygen atoms) [6,12-14] and some macroscopic properties $[7,13,15]$. Thus, this notation will be continued herein.

\subsection{SCC experimental set-up}

SCC techniques invoke a well-documented procedure [16-20] which require DCDC (Double Cleavage Drilled Comparison) sample geometry $\left(5 \times 5 \times 25 \mathrm{~mm}^{3}\right.$ rectangular parallelepiped with a $1 \mathrm{~mm}$ diameter hole which passes through the $5 \times 25 \mathrm{~mm}^{2}$ faces). This geometry provides a decreasing $K_{I}$ as the crack length grows [21,22]. Literature exemplifies stable crack propagation in region 0 and I for DCDC samples [23]. Pallares et al. [21] provides an updated version of He et al. [22] equation to calculate the stress intensity factor $\left(K_{I}\right)$ at the crack tip based on the length of the crack $(c)$ :

$$
K_{I}=\frac{\sigma \sqrt{\pi r}}{\left(a_{0}+a_{1} \frac{w}{r}+a_{2}\left(\frac{w}{r}\right)^{2}\right)+\left(a_{3}+a_{4} \frac{w}{r}+a_{5}\left(\frac{w}{r}\right)^{2}\right) \frac{c}{r}}
$$

where $\sigma=\frac{F}{A}$ is the stress applied to the sample, $A$ is the surface area where the force $F$ is applied, $r$ is the radius of the cylindrical hole, $w$ is the width of the specimen, and $a_{j}(j=0$ to 5 ) are fitting parameters. Pallares et al. [21] calculated the following fitting parameters with Finite Element simulations for Eq. (1): $a_{0}=0.3156, a_{1}=0.7350, a_{2}=0.0346$, $a_{3}=-0.4093, a_{4}=0.3794$, and $a_{5}=-0.0257$.

A Deben compression machine applies the force on the $5 \times 25 \mathrm{~mm}^{2}$ facets. Initially, the applied force increases slowly until two precracks initiate off the hole. The cracks are then allowed to stabilize. Subsequently, the force is set and a tubular microscope coupled with Matlab programs images the crack front's displacement with the applied forces (see Fig. 2 for typical images) continuously. SCC runs occur with no direct control of the temperature nor humidity (i.e. ambient conditions). Researchers manually collected and logged temperature and humidity measurements. SCC experiments lasted from 1 week to 1 month. In order to limit temperature and humidity variations during a single SCC experiment, experiments are conducted in a chamber with limited contact with the external environment. The chamber was located in a room which rests underground and within the center of the building (i.e. none of the walls had direct contact with the outside). The average yearly temperature and humidity in the chamber was $30 \pm 5^{\circ} \mathrm{C}$ and $40 \pm 10 \% \mathrm{RH}$. Appendix A provides an indication of the average temperature and humidity during each experiment.

Post-image analysis provides the $v$ versus $K_{I}$ curves. When calculating the slope in region I, from time to time, outliers occur. These outliners are discarded in the slope calculations. Errors in slopes represent uncertainty obtained from fitting the points.

\subsection{Structural characterization of the glass network}

Barlet et al. [7] presents ${ }^{11} \mathrm{~B}$ magic angle spinning (MAS) nuclear magnetic resonance (NMR) experimental methods and results for the SBN samples. Table 1 recalls the measured ${ }^{11} \mathrm{~B}$ MAS NMR ratios of ${ }^{[4]} \mathrm{B}$ (amount of 4-coordinated boron), ${ }^{[3]} \mathrm{B}$ (amount of 3-coordinated boron) and presented in [6,7]. Post-analysis of ${ }^{11} \mathrm{~B}$ MAS NMR gives 
Table 1

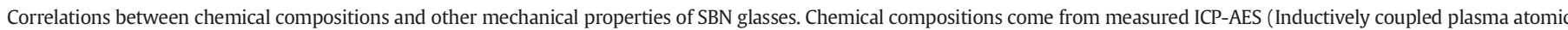

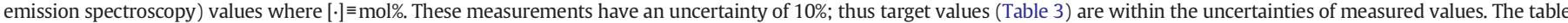

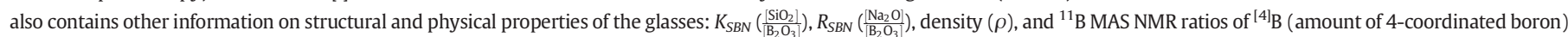



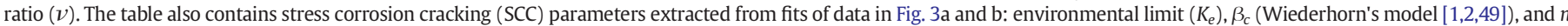
(Maugis's model [86]) for each SBN glass. $E, \nu$, and $\rho$ correspond to the average values and the errors correspond to one standard deviation of the mean of the data.

\begin{tabular}{|c|c|c|c|c|c|c|c|c|c|c|c|c|c|c|c|}
\hline \multirow[b]{2}{*}{ Glass } & \multicolumn{5}{|c|}{ ICP-AES values } & \multicolumn{3}{|c|}{ MAS NMR } & \multirow{2}{*}{$\frac{\rho}{\left(\mathrm{g} / \mathrm{cm}^{3}\right)}$} & \multirow{2}{*}{$\frac{E}{(\mathrm{GPa})}$} & \multirow[b]{2}{*}{$\nu$} & \multicolumn{3}{|l|}{ SCC results } & \multirow[b]{2}{*}{ Symbol } \\
\hline & {$\left[\mathrm{SiO}_{2}\right]$} & {$\left[\mathrm{Na}_{2} \mathrm{O}\right]$} & {$\left[\mathrm{B}_{2} \mathrm{O}_{3}\right]$} & $K_{S B N}$ & $R_{S B N}$ & ${ }^{[4]} \mathrm{B}$ & ${ }^{[3]} \mathrm{B}$ & $N_{N B O}^{[\mathrm{Na2O}]}$ & & & & $K_{e}$ & $\beta_{c}$ & $n$ & \\
\hline SBN12 & $59.6 \%$ & $16.5 \%$ & $23.9 \%$ & 2.5 & 0.69 & $60 \%$ & $40 \%$ & $2.1 \%$ & $2.4619_{ \pm 0.0003}$ & $80.1_{ \pm 0.03}$ & $0.208_{ \pm 0.06}$ & $0.356_{ \pm 0.017}$ & $47_{ \pm 3}$ & $19_{ \pm 1}$ & $A$ \\
\hline SBN30 & $51.0 \%$ & $28.9 \%$ & $20.1 \%$ & 2.5 & 1.4 & $68.9 \%$ & $31.1 \%$ & $15.7 \%$ & $2.5407_{ \pm 0.0001}$ & $74.7_{ \pm 0.05}$ & $0.255_{ \pm 0.001}$ & $0.380_{ \pm 0.019}$ & $56_{ \pm 3}$ & $24_{ \pm 1}$ & $\overline{4}$ \\
\hline SBN35 & $46.9 \%$ & $34.5 \%$ & $18.6 \%$ & 2.5 & 1.9 & $62.2 \%$ & $37.8 \%$ & $24.9 \%$ & $2.5368_{ \pm 0.0001}$ & $76.7_{ \pm 0.04}$ & $0.264_{ \pm 0.002}$ & $0.407_{ \pm 0.012}$ & $93_{ \pm 8}$ & $39_{ \pm 3}$ & $\nabla$ \\
\hline SBN70 & $70.0 \%$ & $14.2 \%$ & $15.8 \%$ & 4.4 & 0.9 & $72 \%$ & $28 \%$ & $2.8 \%$ & $2.4736_{ \pm 0.0003}$ & $81.8_{ \pm 1.02}$ & $0.210_{ \pm 0.015}$ & $0.352_{ \pm 0.015}$ & $49_{ \pm 2}$ & $19.7_{ \pm 0.7}$ & * \\
\hline SBN63 & $66.7 \%$ & $19.2 \%$ & $14.1 \%$ & 4.7 & 1.4 & $81 \%$ & $19 \%$ & $8.0 \%$ & $2.5237_{ \pm 0.0002}$ & $81.87_{ \pm 0.06}$ & $0.226_{ \pm 0.009}$ & & $44_{ \pm 4}$ & $16.4_{ \pm 1.3}$ & $\Delta$ \\
\hline SBN59 & $61.1 \%$ & $25.5 \%$ & $13.3 \%$ & 4.6 & 1.9 & $79.5 \%$ & $20.5 \%$ & $15.9 \%$ & $2.5344_{ \pm 0.0005}$ & $77.15_{ \pm 0.03}$ & $0.230_{ \pm 0.007}$ & & $49_{ \pm 2}$ & $23_{ \pm 1}$ & 0 \\
\hline SBN55 & $58.1 \%$ & $29.1 \%$ & $12.9 \%$ & 4.5 & 2.3 & $76.3 \%$ & $23.7 \%$ & $20.9 \%$ & $2.5383_{ \pm 0.0004}$ & $72.78_{ \pm 0.06}$ & $0.251_{ \pm 0.005}$ & $0.413_{ \pm 0.012}$ & $65_{ \pm 4}$ & $30_{ \pm 2}$ & 逭 \\
\hline
\end{tabular}

way to an estimation of $N_{N B O}$ (number of non-bridging oxygen atoms, NBO) in the SBN glasses. Table 1 presents these results.

Raman measurements employ a YAG laser $(\lambda=532 \mathrm{~nm})$ on a JobinYvon HR800 spectrometer [9,11]. The laser has an adjustable

\section{Crack at $\mathbf{t}$}



\section{Crack at $\Delta t=1365 \mathrm{sec}$}

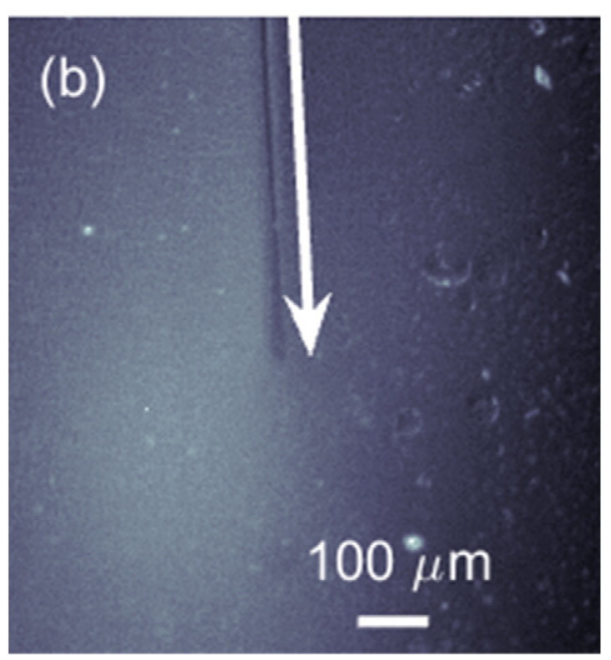

Fig. 2. Typical tubular microscope images of a crack propagating in SBN59. Image (a) was taken at $t_{o}$ and image (b) was taken $1365 \mathrm{~s}$ later. Arrows are offset just to the right of the crack tip and aid in visualizing the crack tip. output power in order to prevent significant heating of the samples. Results herein depict the average of ten measurements accumulated over $10 \mathrm{~s}$. For the $K_{S B N} \sim 2.5$, no clear baseline measurement was feasible within the data set due to the multiple vibrational responses. Hence, the $K_{S B N} \sim 2.5$ spectra still contain the baseline. On the other hand, the $K_{S B N} \sim 4.5$ series did display a similar baseline between the series, so the baseline was removed for data presented herein. Raman spectra merge several different vibrational modes. The interpretation of the co-authors herein relies on comparing and contrasting results found herein with literature [24-41]

\subsection{Density, Poisson's ratio and Young's modulus}

Barlet et al. [6] presents methods to acquire the density $(\rho)$ of a sample using Archimedes principles (see [6] for detailed explanation). These samples were then used in Barlet et al. [7] for ultrasonic echography techniques. The tests use a $5 \mathrm{MHz}$ piezoelectric transducers. Knowing the thickness of the sample (measured via digital micrometer with an accuracy of $\pm 1 \mu \mathrm{m}$ ) and the transit time, one can calculate the longitudinal $\left(V_{L}\right)$ and transverse $\left(V_{T}\right)$ ultrasonic velocities of acoustic waves. Using these values, the Young modulus $(E)$ and the Poisson's ratio $(\nu)$ can be calculated:

$$
E=\rho * \frac{\left(3 V_{L}^{2}-4 V_{T}^{2}\right)}{\left(\frac{V_{L}}{V_{T}}\right)^{2}-1}
$$

$\nu=\frac{V_{L}^{2}-2 V_{T}^{2}}{2\left(V_{L}^{2}-V_{T}^{2}\right)}$

Table 1 presents $E, \nu$ and $\rho$ for the SBN samples.

\subsection{MD simulations}

Molecular Dynamics (MD) simulations provide researchers with the structural organization of ternary $\mathrm{SiO}_{2}-\mathrm{B}_{2} \mathrm{O}_{3}-\mathrm{Na}_{2} \mathrm{O}$ glass systems. MD simulations herein use empirical interatomic potentials developed by Kieu et al. [42,43] for SBN glasses. These potentials incorporate Buckingham's potential with Coulomb interactions via an Ewald sum [44]. Guillot-Sator potential parameters describe the $\mathrm{Si}-\mathrm{O}, \mathrm{Na}-\mathrm{O}$ and $\mathrm{O}-\mathrm{O}$ interactions [45]. The parameters for the $\mathrm{B}-\mathrm{O}$ interactions have been adjusted to fit density and elastic modulus properties on a large set of $\mathrm{SiO}_{2}-\mathrm{B}_{2} \mathrm{O}_{3}-\mathrm{Na}_{2} \mathrm{O}$ glasses. All the calculations invoke DLPOLY code [46].

Formation of the glassy network occurs by giving $1500 \mathrm{Si}, \mathrm{B}, \mathrm{O}$, and $\mathrm{Na}$ atoms random locations in a cube at $4000 \mathrm{~K}$. The density of the systems was $5 \%$ lower than experimental densities in order to reach a final 

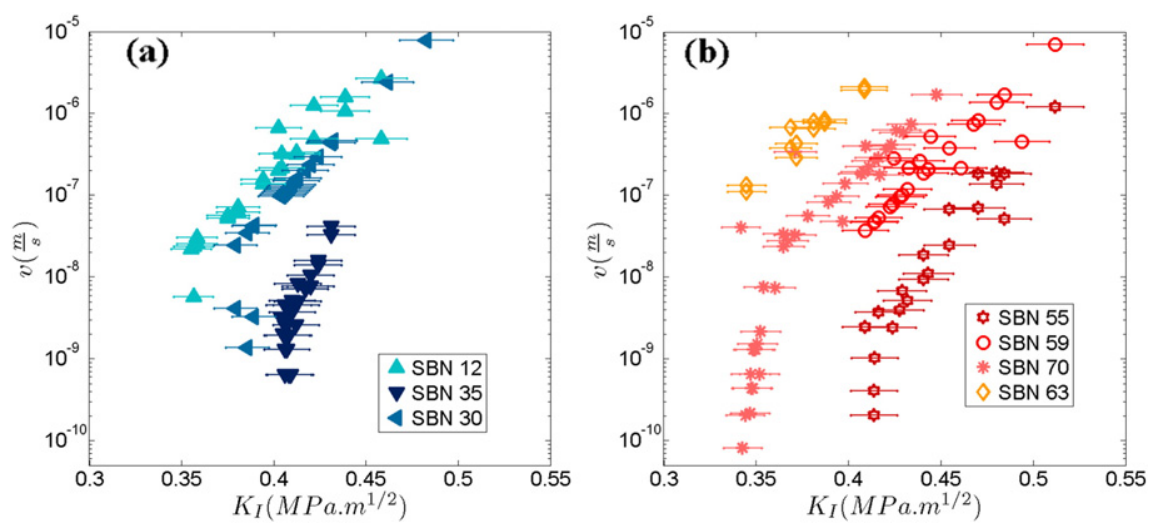

Fig. 3. Stress corrosion cracking results in region 0 and I: (a) $K_{S B N} \sim 2.5$ and (b) $K_{S B N} \sim 4.5$.

density close to the experimental one. The system relaxation occurred over a period of $100 \mathrm{ps}$ (time steps were $1 \mathrm{fs}$ ).

Subsequently, the glasses fabrication occurs via quenching the systems to $300 \mathrm{~K}$ at a rate of $5 \times 10^{12} \mathrm{~K} / \mathrm{s}$. A three step process occurs at this point in order to obtain the structure of the glasses. First, volume equilibration occurs via NPT calculation $\left(2 \times 10^{4}\right.$ time steps). Second, holding the volume constant (determined by the previous step), NVE ensemble simulations enable the atoms to equilibrate around their equilibrium sites. This step occurs for 5000 time steps. Finally, the forces between the atoms are minimized via a steepest descent algorithm. Structural averaging occurs on 11 configurations separated by 500 time steps. These 11 configurations come about after a steepest descent to $0 \mathrm{~K}$ and occur via an equilibration at $0 \mathrm{~K}$. For each chemical composition, four independent trajectories improve the statistics.

This process is repeated for all target compositions presented in Table 3. (Note: Barlet et al. [6] presents multiple simulated MD glasses. The co-authors selected 6 of the glasses for experimental SCC test. Additionally, one extra sample SBN63 was selected for SCC experimental tests, but parallel MD simulations were not preformEd.) A detailed comparison between experimental and simulated structural data for the $\mathrm{SiO}_{2}-\mathrm{B}_{2} \mathrm{O}_{3}-\mathrm{Na}_{2} \mathrm{O}$ glass systems is available in references [6,43]. In order to quantify the reticulation level, the degree of polymerization (DP) at the atomic level a new parameter is introduced. The parameter uses the following equation:

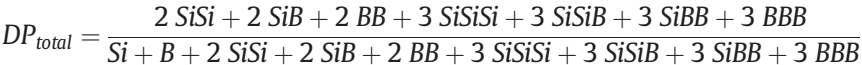

Variables correspond to the types of atoms associate to $\mathrm{O}$ atoms. (e.g. $\mathrm{SiB}$ corresponds to oxygen atoms between a $\mathrm{Si}$ atom and a B atom. SiSiB corresponds to over coordinated oxygen atoms with $2 \mathrm{Si}$ atoms and $1 \mathrm{~B}$ atom in the vicinity. Si corresponds to under coordinated oxygen, i.e. non-bridging oxygen (NBO) atom, atom with $1 \mathrm{Si}$ atom.) Table 4 presents all variables used in Eq. (4). MD simulations easily enable the counting of these types of variables via a cut-off.

For glass former ( $\mathrm{Si}$ or $\mathrm{B}$ ) to be bonded to an $\mathrm{O}$ atom, it must lie within a cut-off radii of $2.1 \AA$ and $2.0 \AA \AA$ for $\mathrm{Si}$ and $\mathrm{B}$ atoms respectively. Loose $\mathrm{O}$ atoms (i.e. an $\mathrm{O}$ atom not connected to any former) do not occur. Only, a small number of three coordinated $\mathrm{O}$ atoms arise in some glassy compositions. Yet, the definition of $D P_{\text {total }}$ includes them. If $D P_{\text {total }}=1$, then the glass is fully polymerized (i.e. all $\mathrm{O}$ atoms are bounded to 2 or more network formers). If $D P_{\text {total }}<1$, then the glass has some depolymerization (i.e. the smaller is $D P_{\text {total }}$, the more depolymerized the glass is). Similarly to Eq. (4) the contribution to the degree of polymerization for each network former is:

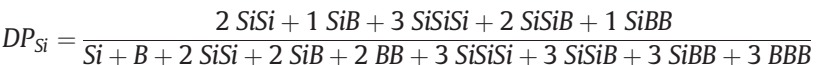

for the silica units and

$D P_{B}=\frac{1 S i B+2 B B+1 S i S i B+2 S i B B+3 B B B}{S i+B+2 S i S i+2 S i B+2 B B+3 S i S i S i+3 S i S i B+3 S i B B+3 B B B}$

for the boron units.

Data shown in Fig. 9 originates from fracture simulations on SBN systems [42]. These simulations invoked the same potentials as described above. Fracture simulation details can be found in reference [47].

\section{Results}

\subsection{SCC behavior as a function of chemical composition}

Fig. 3 depicts the curves $v$ vs. $K_{I}$ characteristic of the SCC response for the glass composition under consideration herein for constant $K_{S B N}$ : (a) $K_{S B N} \sim 2.5$ and (b) $K_{S B N} \sim 4.5$. The axes are semi-logarithmic. The curves exhibit the shape expected from literature [1,4], with a sharp jump of $v$ at the environmental limit $K_{e}$ (region 0 ) followed by an exponential increase of $v$ with $K_{I}$ (region I). Variations occur with the glass's chemical composition. The amount of $\left[\mathrm{Na}_{2} \mathrm{O}\right]$ drives these changes.

\subsubsection{Region 0}

First, the SCC curves shift to higher $K_{e}$ values as [ $\mathrm{Na}_{2} \mathrm{O}$ ] increases (see Fig. 4 and Table 1). Note that neither SBN59 nor SBN63 display a clear threshold. Applying lower $K_{I}$ values to both glasses did not produce a measurable variation in the length of the crack tip. For the other glasses with a clear observable threshold, $K_{e}$ increases roughly linearly with the amount of sodium in the system. This means that in general a SBN



Fig. 4. The evolution of $K_{e}$ as $\left[\mathrm{Na}_{2} \mathrm{O}\right]$ increases. 



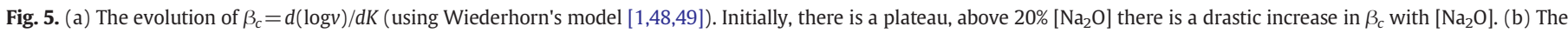
evolution of $n=d(\log v) / d(\log K)$ (using Maugis's model [86]) displays similar results.

glass's resistance to the onset of SCC (ability to sustain higher loads without sub-critical crack propagation) increases as $\left[\mathrm{Na}_{2} \mathrm{O}\right]$ increases. The role played by alkali content on the value of $K_{e}$ is highlighted in the literature. Section 4.1 provides a discussion of the various mechanisms proposed to explain this observation.

\subsubsection{Region I}

The slope of the $v$ vs. $K$ curve in region I steepens as $\mathrm{Na}_{2} \mathrm{O}$ increases. The curve in this region I is classically modeled either by Wiederhorn's exponential law derived from the reaction-rate theory $[1,4,48,49]$ :

$v=v_{o} \exp \left(\beta_{c} \mathrm{~K}\right)$

or by Maugis power law:

$v=v_{o}\left(\frac{K}{K_{0}}\right)^{n}$

Within these two frameworks, $\beta_{c}=d(\log v) / d K$ and $n=d(\log v) /$ $d(\log K)$ defines the steepness of the SCC curves. Table 1 presents results on $\beta_{c}$ and $n$ computed for the 7 SBN glasses herein. Fig. 5 presents their evolution with $\left[\mathrm{Na}_{2} \mathrm{O}\right]$. Initially, the amount of sodium does not significantly alter the slope; however, as [ $\left.\mathrm{Na}_{2} \mathrm{O}\right]$ increases above $20 \%$ the slope drastically increases. This means that the corrosion speed once SCC is triggered (i.e. when $K>K_{e}$ ) increases as [ $\mathrm{Na}_{2} \mathrm{O}$ ] increases: A step of $0.02 \mathrm{MPa} . \sqrt{\mathrm{m}}$ in $K_{I}$ implies an increase in the velocity of $\sim 150 \%$ for SBN12 $\left(\left[\mathrm{Na}_{2} \mathrm{O}\right]=12.2 \%\right)$ and $\sim 550 \%$ for the SBN35 $\left(\left[\mathrm{Na}_{2} \mathrm{O}\right]=30 \%\right)$. Literature does document the role of the chemical composition on $K_{e}$; on the other hand, the role of the glass's chemical composition on the slopes $\beta_{c}$ and $n$ remains virtually undocumented.
3.2. Effect of chemical composition on the relative proportion of chemical bonds, in contrast with that on SCC

Since the pioneering work of Charles and Hillig's [50], the $v$ vs. $K$ curve in region I is usually modeled via the chemical reaction rate theory $[1,4$, 48-50], which explains the exponential dependency of $v$ with $K_{I}$. In this framework, the nature and proportion of chemical bonds encountered in the corroding glass selects $v$. Furthermore, many researchers cite the $\mathrm{Si}-\mathrm{O}-\mathrm{Si}$ bond to be the limiting factor in the propagation of the crack front [51-54]. If this is true, then there should be a clear dependency on the number of bonds versus the slope in Region I. As stated in Section 2.5, MD simulations enable the counting of the number of bonds in the SBN systems. Counting, comparing and contrasting these variables to $\beta_{c}$ and $n$ aids in confirming or refuting the long standing hypothesis that the $\mathrm{Si}-\mathrm{O}-\mathrm{Si}$ bond controls the crack propagation.

Fig. 6 depicts the normal coordinated bridging oxygen atoms of different nature and $\beta_{c}$. These figures reveal the lack of generic trends. Similar results occur for $n$. The nature and relative proportion of chemical bonds formed by bridging oxygen atoms in the SBN glasses are not the key parameters responsible for selecting the SCC behavior in region I.

A few over coordinated oxygen atoms (i.e. oxygen atoms with 3 network formers in their vicinity) exist in the systems. However, they are extremely rare $(<2 \%$ total, i.e. considering all of the 0 atoms in the glasses, in low sodium glasses and $<1 \%$ in high sodium glasses). No correlation exists between the number of over coordinated oxygen atoms and the slope in region I.

Moving to a more mesoscale parameter, $D P_{S i}$ and $D P_{B}$ reveal the partial glass depolymerization for the Silica and Borate units, respectively. Fig. 7 depicts these results with $\beta_{c}$. Similar figures exist when considering $n$. When separating the two $K_{S B N}$ values, $\beta_{c}$ increases somewhat with depolymerization.
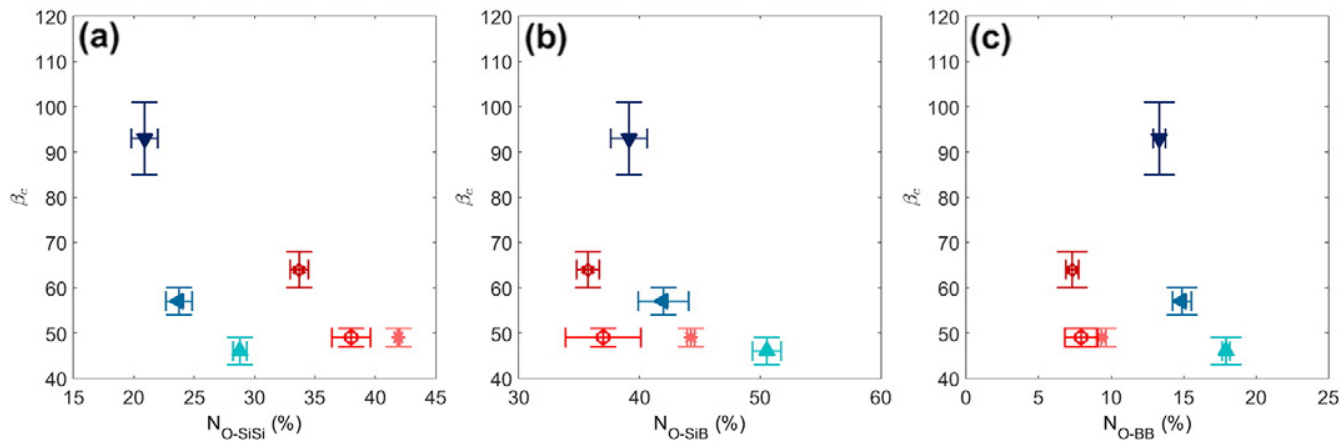

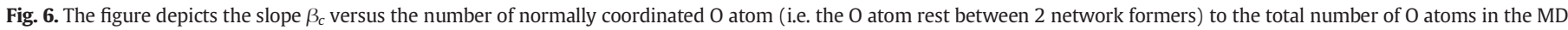


fraction of oxygen atom between two $\mathrm{B}$ atoms. 

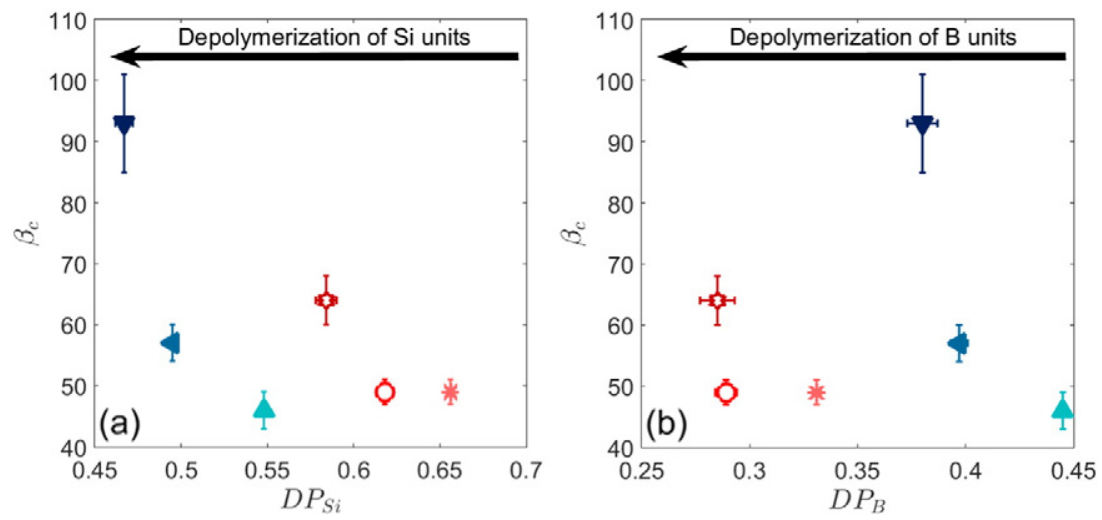

Fig. 7. The figure depicts the slope versus the index of depolymerization as define by Eq. (5) (a) and Eq. (6) (b) for the silica and borate units, respectively.

On the other hand, considering the glass as a whole and calculating $D P_{\text {Total }}$ reveals a clear trend. Moreover, there is a collapse of the data for the two different $K_{S B N}$ values. Increasing the polymerization of the glass decreases $\beta_{c}$ until $D P_{\text {Total }} \cong 0.91$ afterwards $\beta_{c}$ is constant within the error of the data. Similar trends exist when looking at the variation of $n$ with $D P_{\text {Total }}$.

Another way to catalog the degree of depolymerization in the glasses is by the number of non-bridging oxygens (NBO). Fig. $8 \mathrm{~b}$ reveals $\beta_{c}$ dependency on the total number of NBO atoms in the system. A clear trend exists, similar trends exist when considering $n$. Initially, $\beta_{c}$ is independent of the number of NBOs up until about $17 \%$. Afterwards, $\beta_{c}$ increases drastically with the number of NBOs in the glass. Herein both the total number of NBOs and $D P_{\text {Total }}$ are measures of the degree of depolymerization of the glass network. Both variables lead to a similar conclusion that the degree of depolymerization is the relevant structure parameter responsible for the selection of SCC behavior (characterized by the slopes $\beta_{c}$ and $n$ ).

\subsection{Bonds broken in the wake of the crack front}

Furthermore, MD simulations enable scientists to count the number of $\mathrm{Si}-\mathrm{O}$ and $\mathrm{B}-\mathrm{O}$ bonds broken by a crack front. MD simulation performed on SBN glasses (with chemical compositions similar to the ones used herein) found the number of $\mathrm{B}-\mathrm{O}$ and $\mathrm{Si}-\mathrm{O}$ bonds broken (for constant $K_{S B N}$ ) to decrease with increasing sodium content (Fig. 9) $[42,47]$. Albeit 2-D, simulations of similar glasses do reveal potential crack paths which never have to break $\equiv \mathrm{Si}-\mathrm{O}-\mathrm{Si} \equiv$ bonds. Thus, the probability to break a $\equiv \mathrm{Si}-\mathrm{O}-\mathrm{Si} \equiv$ decreases with increasing $\left[\mathrm{Na}_{2} \mathrm{O}\right]$ content.
Hence, in this series of glasses, breaking of the $\equiv \mathrm{Si}-\mathrm{O}-\mathrm{Si} \equiv$ bond should not be the limiting factor.

\subsection{Effect of chemical composition on the glass network, in correlation with} that on SCC

Several papers $[6,12,13,15]$ detail how $\left[\mathrm{Na}_{2} \mathrm{O}\right]$ modifies the $\left[\mathrm{SiO}_{2}\right]-$ $\left[\mathrm{B}_{2} \mathrm{O}_{3}\right]$ network. Initially, small amounts of $\left[\mathrm{Na}_{2} \mathrm{O}\right]$ transforms planar ${ }^{[3]} \mathrm{B}$ units into ${ }^{[4]} \mathrm{B}$ for $R_{S B N}<R_{\max }=0.5+\frac{K_{S B N}}{16}$. Subsequently, the sodium attacks the Silica network adding non-bridging oxygen atoms (NBO) to Silica tetrahedrons for $R_{S B N}<R_{d 1}=0.5+0.25 \times K_{S B N}$. For $R_{S B N}>R_{d 1}$, sodium attacks both the silica and boron network by forming NBO on silica tetrahedrons and transforming ${ }^{[4]} \mathrm{B}$ units back into planar ${ }^{[3]} \mathrm{B}$ units with one or more NBO. Table 2 presents the fractional quantities of these elementary units calculated from Barlet et al. [6]. Raman and NMR analysis enable researchers to gain additional insight into the glass structure along with confirming and extending the insights provided by MD simulations.

Fig. 10 presents Raman spectra for the two different $K_{S B N}$ series. Clearly, the chemical composition (along with the increasing $\mathrm{Na}_{2} \mathrm{O}$ concentration) alters the Raman response of the glasses: (1) a shift of the main $\mathrm{Si}-\mathrm{O}-\mathrm{Si}$ band at $430 \mathrm{~cm}^{-1}$ towards higher frequencies; (2) a reduction in borate-ring and borosilicate-ring features between $550-$ $850 \mathrm{~cm}^{-1}$, (3) a change in the $Q_{n}$ contribution around $900-$ $1200 \mathrm{~cm}^{-1}$; and (4) an increase in the $\mathrm{B}-\mathrm{O}^{-}$peak at $1450 \mathrm{~cm}^{-1}$. Literature links these effects to several scenarios: (1) an increase in the NBOs on the silica tetrahedral [25]; (2) an increase in the depolymerization degree predicted by Yun, Dell and Bray model [12,55,56]; and (3) an increase in the mixing of the silica and borate networks evidenced by the
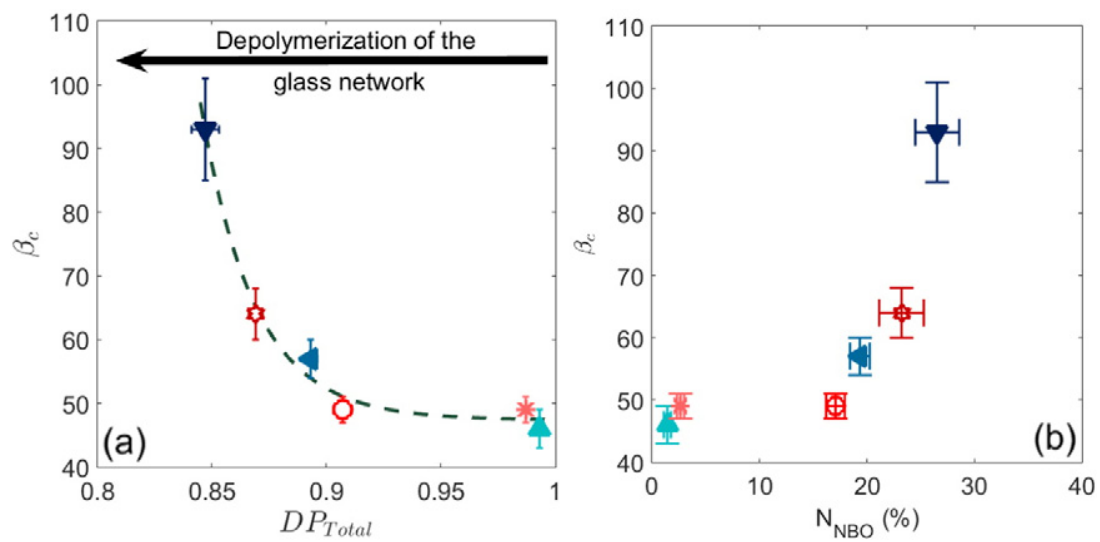

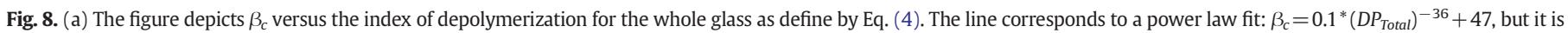
predominantly for aiding the eye. (b) The figure depicts $\beta_{c}$ versus the percentage of NBOs calculated from MD simulations. 




Fig. 9. The image presents the number of $\mathrm{B}-\mathrm{O}$ (green dash dot line), $\mathrm{Si}-\mathrm{O}$ (red dashed) bonds broken and their sum (blue dotted line) as measured from Molecular Dynamics simulations $[42,47]$. The plus (SBN70) and star (SBN55) correspond to similar $K_{S B N}$ numbers. The triangle SBN12 corresponds to another $K_{S B N}$ series.

increase in the danburite peak ( $633 \mathrm{~cm}^{-1}$ band) and decrease in the borate rings [26]. Another scenario evidenced in literature, but less likely due to the $\left[\mathrm{Na}_{2} \mathrm{O}\right]$, is a decrease in the silica ring sizes associated with a shift in the $430 \mathrm{~cm}^{-1}$ band to higher frequencies [25,27-29].

${ }^{11} \mathrm{~B}$ MAS NMR studies provide estimates for the number of NBO atoms in these glasses [7]. Fig. 11 displays the variation of the NBO atoms calculated from Barlet et al. [7] with respect to $\left[\mathrm{Na}_{2} \mathrm{O}\right]$. Comparing and contrasting these results with Barlet et al. [6] gives several interesting conclusions about the local glass structure. Sodium in both SBN12 $\left(\left[\mathrm{Na}_{2} \mathrm{O}\right]=12.2 \%\right)$ and SBN70 $\left(\left[\mathrm{Na}_{2} \mathrm{O}\right]=14.2 \%\right)$ act as network compensators causing ${ }^{[3]} \mathrm{B}$ units to swap to ${ }^{[4]} \mathrm{B}$ units. For SBN63 $\left(\left[\mathrm{Na}_{2} \mathrm{O}\right]=20 \%\right)$, $\left[\mathrm{Na}_{2} \mathrm{O}\right]$ acts as a network compensators to the boron network $\left({ }^{[3]} \mathrm{B}\right.$ units to swap to ${ }^{[4]} \mathrm{B}$ ) and a network modifier to the silica network (NBO atoms on silica tetrahedron). For the remaining glasses $\left(\left[\mathrm{Na}_{2} \mathrm{O}\right] \geq 25 \%\right)$, the sodium acts as a network modifier to both the silica (adding NBO atoms to the silica network) and boron (causing ${ }^{[4]} \mathrm{B}$ units to change back into ${ }^{[3]} \mathrm{B}$ units with $\mathrm{NBO}$ atoms and a $\mathrm{Na}^{+}$in the vicinity for charge compensation) units. This now permits a novel interpretation of the variations of the SCC slopes observed in Fig. 5:

- For SBN glasses with low amount of $\left[\mathrm{Na}_{2} \mathrm{O}\right]$ (typically $R_{S B N} \leqslant R_{\max }=$ $\left.0.5+\frac{K_{S B N}}{16}\right), \mathrm{Na}^{+}$ions act predominantly as network compensators, the number of $\mathrm{NBO}$ atoms is independent of $\left[\mathrm{Na}_{2} \mathrm{O}\right]$, and hence, $\beta_{c}$ (or $n$ ) are constant.

- For SBN glasses with an intermediate amount of $\left[\mathrm{Na}_{2} \mathrm{O}\right]$ (typically $R_{\max } \lesssim R_{S B N} \lesssim R_{d 1}=0.5+0.25 K_{S B N}$ ), $\mathrm{Na}^{+}$ions act predominantly as network compensators on the borate network and as modifiers on the silicate network. The number of NBO atoms begin to
Table 3

The table presents the target molar percentages corresponding to the values used for MD simulations. The quantity of each atomic species is specified.

\begin{tabular}{llllllll}
\hline Glass & $\mathrm{SiO}_{2}$ & $\mathrm{Na}_{2} \mathrm{O}$ & $\mathrm{B}_{2} \mathrm{O}_{3}$ & $\mathrm{Si}$ & $\mathrm{Na}$ & $\mathrm{B}$ & $\mathrm{O}$ \\
\hline SBN12 & 59.6 & 12.2 & 28.2 & 251 & 103 & 237 & 909 \\
SBN30 & 47.4 & 30.2 & 22.4 & 206 & 263 & 195 & 836 \\
SBN35 & 44.1 & 35.45 & 20.45 & 194 & 312 & 180 & 814 \\
SBN70 & 67.7 & 14.1 & 18.2 & 302 & 126 & 162 & 910 \\
SBN59 & 59.1 & 25.0 & 15.9 & 267 & 226 & 144 & 863 \\
SBN55 & 55.2 & 30.0 & 14.8 & 251 & 273 & 135 & 841 \\
\hline
\end{tabular}

slightly increase, $\beta_{c}$ (or $n$ ) decrease slightly but remain constant within a 95\% (2.5 $\sigma$, where $\sigma$ is the width of the distribution presented in Table 1) confidence error. It is well noted that only one sample herein truly show signs of being in this region, SBN63. Thus, more extensive studies are required to understand glasses in this region.

- For SBN glasses with large enough amounts of $\left[\mathrm{Na}_{2} \mathrm{O}\right]$ (typically $\mathrm{R}_{\mathrm{SBN}}>R_{d 1}=0.5+0.25 K_{S B N}$ ), $\mathrm{Na}^{+}$ions mainly act as network modifiers on the silica and borate network. The number of $\mathrm{NBO}$ atoms increases with $\left[\mathrm{Na}_{2} \mathrm{O}\right]$ (roughly linearly, Fig. 11) and $\beta_{c}$ ( or $n$ ) increases significantly (see Fig. 8b).

\subsection{Poisson ratio an indicator of the sodium content but not of the SCC behavior}

The Poisson ratio, $\nu$, is a continuum-level scale mechanical parameter, which embeds into itself information concerning the depolymerization of the glassy network, NBO atoms... [57]. Furthermore, Barlet et al. [7] showed that $\nu$ was the main parameter driving the response of SBN glass under indentation. Along these lines, a natural comparison would be to compare $\nu$ with that of the SCC behavior in region I.

Fig. 12 depicts the evolution of $\nu$ with [ $\mathrm{Na}_{2} \mathrm{O}$ ] [7]. As reported in [7], $\nu$ is roughly proportional to $\left[\mathrm{Na}_{2} \mathrm{O}\right]$. Fig. 13 depicts the $\beta_{c}$ versus $\nu$. When sodium acts predominantly as a modifier (typically $R_{S B N} \lesssim R_{\max }=0.5+$ $\left.\frac{K_{S B N}}{16}\right)$, as in the case of SBN12 and SBN70, $\beta_{c}$ is rather constant with $\nu$. Afterwards, the sodium begins to act as a charge compensator on the silicate network or on the silicate and borate network. At this transition, $\beta_{c}$ increases drastically with $\nu$. This demonstrates that SCC in region I depends not only on how much $\left[\mathrm{Na}_{2} \mathrm{O}\right]$ is in the sample, but also on the role of sodium (modifier or charge compensator) in the glass. Thus, only considering $\nu$ (or $\left[\mathrm{Na}_{2} \mathrm{O}\right]$ ) at the continuum scale does not easily exemplify a glass's SCC response in region I.

\section{Discussion}

\subsection{Region 0 - origins of the environmental shift with sodium oxide}

Region 0 , or the environmental limit $\left(K_{e}\right)$, displays a minimal stress required for a crack front to propagate. Not all glasses have an environmental limit, e.g. pure silica. For materials with non-existing regions 0 , no

Table 2

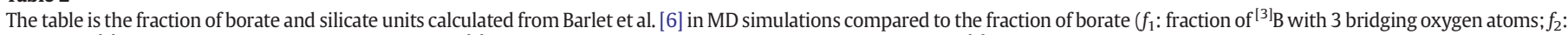



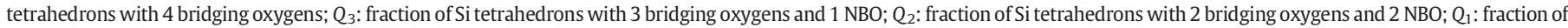
Si tetrahedrons with 1 bridging oxygens and 3 NBOs; and $Q_{0}$ : fraction of Si tetrahedrons with 4 NBO) units from theory for systems of interest.

\begin{tabular}{|c|c|c|c|c|c|c|c|c|c|c|c|c|}
\hline Glass & $\mathrm{SiO}_{2}$ & $\mathrm{Na}_{2} \mathrm{O}$ & $\mathrm{B}_{2} \mathrm{O}_{3}$ & $f_{1}$ & $f_{2}$ & $f_{3}$ & $f_{4}$ & $Q_{4}$ & $Q_{3}$ & $Q_{2}$ & $Q_{1}$ & $Q_{0}$ \\
\hline SBN12 & $59.60 \%$ & $16.50 \%$ & $23.90 \%$ & 0.34 & 0.66 & 0 & 0 & 0.97 & 0.03 & 0 & 0 & 0 \\
\hline SBN30 & $51.00 \%$ & $28.90 \%$ & $20.10 \%$ & 0.30 & 0.60 & 0.03 & 0.07 & 0.47 & 0.51 & 0.01 & 0 & 0 \\
\hline SBN35 & $46.90 \%$ & $34.50 \%$ & $18.60 \%$ & 0.23 & 0.52 & 0.07 & 0.18 & 0.29 & 0.67 & 0.04 & 0 & 0 \\
\hline SBN70 & $70.00 \%$ & $14.20 \%$ & $15.80 \%$ & 0.22 & 0.78 & 0 & 0 & 0.94 & 0.06 & 0 & 0 & 0 \\
\hline SBN63 & $66.70 \%$ & $19.20 \%$ & $14.10 \%$ & 0.20 & 0.80 & 0 & 0 & 0.76 & 0.24 & 0 & 0 & 0 \\
\hline SBN59 & $61.10 \%$ & $25.50 \%$ & $13.30 \%$ & 0.20 & 0.74 & 0.01 & 0.05 & 0.53 & 0.46 & 0.01 & 0 & 0 \\
\hline SBN55 & $58.10 \%$ & $29.10 \%$ & $12.90 \%$ & 0.18 & 0.68 & 0.03 & 0.11 & 0.41 & 0.57 & 0.02 & 0 & 0 \\
\hline
\end{tabular}


Table 4

The table presents variables used in Eq. (4).

\begin{tabular}{|c|c|}
\hline $\begin{array}{l}\text { Variables } \\
\text { in } \\
\text { Eq. (4) }\end{array}$ & Meaning \\
\hline $\mathrm{Si}$ & Number of non-bridging $\mathrm{O}$ atoms near one $\mathrm{Si}$ atom \\
\hline$B$ & Number of non-bridging $\mathrm{O}$ atoms near one $\mathrm{B}$ atom \\
\hline SiSi & Number of 2 -coordinated $\mathrm{O}$ atoms surrounded by $2 \mathrm{Si}$ atoms \\
\hline $\mathrm{SiB}$ & $\begin{array}{l}\text { Number of 2-coordinated } \mathrm{O} \text { atoms surrounded by } 1 \mathrm{Si} \text { atom and } 1 \mathrm{~B} \\
\text { atom }\end{array}$ \\
\hline$B B$ & Number of 2-coordinated $\mathrm{O}$ atoms surrounded by $2 \mathrm{~B}$ atoms \\
\hline SiSiSi & Number of 3-coordinated $\mathrm{O}$ atoms surrounded by $3 \mathrm{Si}$ atoms \\
\hline SiSiB & $\begin{array}{l}\text { Number of 3-coordinated } \mathrm{O} \text { atoms surrounded by } 2 \mathrm{Si} \text { atoms and } 1 \mathrm{~B} \\
\text { atom }\end{array}$ \\
\hline $\operatorname{SiBB}$ & $\begin{array}{l}\text { Number of 3-coordinated } \mathrm{O} \text { atoms surrounded by } 1 \mathrm{Si} \text { atom and } 2 \mathrm{~B} \\
\text { atoms }\end{array}$ \\
\hline BBB & Number of 3-coordinated $\mathrm{O}$ atoms surrounded by $3 \mathrm{~B}$ atoms \\
\hline
\end{tabular}

matter how small the stress at the crack tip, the crack will always propagate. On the other hand, glasses with alkali atoms do exhibit an environmental limit $[3,4,58]$, as in the case herein. Lawn links the delayed onsets of crack propagation to a shielding zone which encompasses the crack tip [59]. Thus, the physical properties of the glass and crack front within this shielding zone (or process zone, PZ) dictate the response. There are several mechanisms behind the $K_{e}$ shift hypothesized in literature:

- Enhanced diffusion of alkali atoms due to stresses which provide the energy necessary for alkali atoms to migrate out of the PZ to the crack tip or free surfaces of the sample [54].

- Hydronium- $\mathrm{Na}^{+}$exchange causing a compression in the PZ due to the larger size of the hydronium ions [58,60,61].

- Blunting of the crack tip [58].

- Build-up of a leaching layer which prevents water from attacking the glass network [58].

- Variations in the $\mathrm{pH}$ at the crack tip [58,62-64].

All of these mechanisms suggest that $K_{e}$ should increase as [ $\left.\mathrm{Na}_{2} \mathrm{O}\right]$ increases for approximately constant $K_{S B N}$. As such, they are consistent with our measurements (see Fig. 4).

Although the mechanisms suggested in literature are feasible, contemplating the model SBN glasses herein uncover possible novel scenarios. Increasing $\left[\mathrm{Na}_{2} \mathrm{O}\right]$ leads to an increase in $\mathrm{NBO}$ atoms on the silica network and eventually the return of planar ${ }^{[3]} \mathrm{B}$ units but with NBO atoms. This aids in shifting $K_{e}$ to higher stress intensity factors. Kieu et al. [65] shows that the planar ${ }^{[3]} B$ units can accommodate stresses by reorienting themselves due to an increase in their degrees of freedom. One can also conjecture that NBO on ${ }^{[3]} \mathrm{B}$ units further increases the degrees of freedom on these units due to the decrease in polymerization of the glass.
Rountree et al. [66] showed that mechanical loading of pure silica can endow the structure with an orientational order. Furthermore, Smedskjaer et al. [67] attribute floppy modes in $\mathrm{SiO}_{2}-\mathrm{Na}_{2} \mathrm{O}$ glasses with $\mathrm{NBO}$ atoms on silica tetrahedrons [68-72]. Thus, one can conjecture that $\mathrm{NBO}$ on ${ }^{[4]} \mathrm{Si}$ units has several effects: (1) increases the degrees of freedom on ${ }^{[4]} \mathrm{Si}$ units; (2) decreases the polymerization of the glass; and (3) increases the plasticity of the glass. These effects would aid in shifting $K_{e}$ to higher values.

Literature exemplifies the formation of preferential paths/channels/ pockets for glasses enriched in sodium $[65,73,74]$. It is well know that the process zone [59] along with the shape of the crack tip [75] aid in diffusing stresses. It is conjectured herein that the formation of preferential paths/channels/pockets, which enable the diffusion of $\mathrm{Na}^{+}$ions, act as stress sinks (i.e. they diffuse stresses at the crack tip), and thus delay the onset of crack propagation.

Another scenario arises from the increase in the glass plasticity due to $\mathrm{Na}^{+}$ions acting as network modifiers (rather than compensators). It is interesting to recall Grandjean et al. [76] studies show that the diffusion coefficient of $\mathrm{Na}^{+}$as a modifier is larger than the diffusion coefficient of $\mathrm{Na}^{+}$as a charge compensator. Invoking micro-indentation tests on these glasses revealed a shift in mechanical processes from densification to isochoric shear flow as $\left[\mathrm{Na}_{2} \mathrm{O}\right]$ increases $[10,77,78]$. Rouxel and coworkers link these changes to the glass Poisson ratio which is linked to the packing fraction and depolymerization of the glasses [77,78].

It is worth noting again that this set of experiments only reveals possible processes within the process zone, it is unable to discriminate the dominant effect. Further studies are needed to isolate and possibly quantify the dominant effects.

\subsection{Region I - dependence of the slope on one particular bond in the glass}

For $K_{S B N}$ approximately constant, $\beta_{c}$ (and $n$ ) increases with increasing $\left[\mathrm{Na}_{2} \mathrm{O}\right]$ concentration (Fig. 5). In the 1960s and early 1970s, many papers state that crack front propagation occurs via heterogeneous chemical reactions occurring at the crack tip [1,50]. Glastone et al. [79] (which was restated by Wiederhorn in reference [1]) summarized the reactions occurring on a surface via 5 successive steps (taken from reference [1]):

- "Movement of the gas reactant to the surface

- Surface adsorption of the gasses

- Reaction of the surface with the gas

- Desorption of the products on the surface

- Transferring the freed product from the surface into the process zone."

The limiting factor of the reaction is the slowest, and this slowest reaction is the one defining the velocity of the crack front. In such a scenario, the rupture of the $\mathrm{Si}-\mathrm{O}$ bond is expected to be the limiting factor [80]. Hence, there should be a clear dependence on the number of bonds versus the slope in region I. Our analysis refutes this scenario

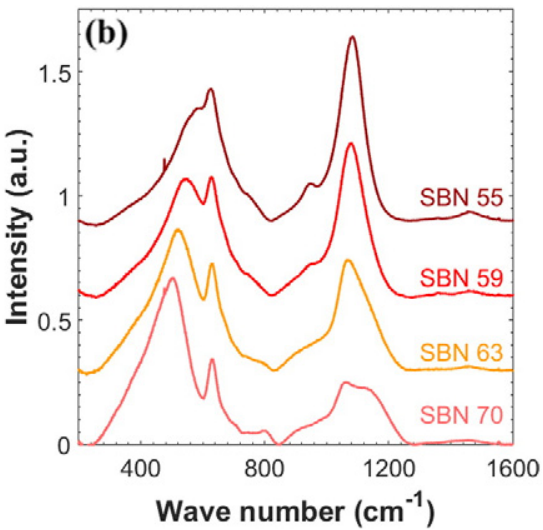

Fig. 10. The image presents Raman results concerning the $K_{S B N} \sim 2.5$ (a) and $K_{S B N} \sim 4.5$ (b) series. The curves have been offset from each other for visualization. 
since no correlation occurs between the SCC curve in region I (parameters $\beta_{c}$ and $n$ ) and the relative proportion of chemical bonds formed by bridging oxygen (Fig. 6). Furthermore, the depolymerization of just the silica or borate units fails to reveal a trend (Fig. 7). Yet, the depolymerization of the full network reveals a clear trend after an initial threshold value (Fig. 8a). This shows that the mesoscale should be considered rather than just one type of bond.

\subsection{Region I and the reaction rate theory}

From the reaction rate theory, Wiederhorn et al. proposed to link the slope in region I to an activation volume $\Delta V^{*}[49,62]$. From [48,49], $\beta_{c}$ is proportional to the activation volume, $\Delta \mathrm{V}^{*}$ and inversely proportional to $\sqrt{\rho_{\mathrm{ct}}}$ (where $\rho_{\mathrm{ct}}$ is the crack tip radius). Inverse proportionality of $\sqrt{\rho_{\mathrm{ct}}}$ with $\beta_{\mathrm{c}}$ implies that the slope increases while the crack tip radius gets smaller. Yet, as the sodium content increases the crack tip blunts more [81] or shows no variation [82]. These two ideas are inconsistent with our data. Turning to $\Delta V^{*}, \Delta V^{*}$ represents a variation in volume between the activated complex (with water molecule) and the unreacted state. In general, the Young modulus varies from 72 to $82 \mathrm{GPa}$ and the Poisson ratio from 0.21 to 0.26 . The change is too slight to expect such a huge increase in $\beta_{c}$. Thus, the reaction rate theory cannot explain the increase in $\beta_{c}$ in SBN glasses.

\subsection{Region I and SCC driven by water diffusion}

Tomozawa concluded that the diffusion of water into the crack tip aids sub-critical crack propagation. Moreover, this decreases the toughness and permits crack propagation [83]. Fig. $5 \mathrm{a}$ and b depicts $\beta_{c}$ and $n$ with [ $\left.\mathrm{Na}_{2} \mathrm{O}\right]$. Increasing $\left[\mathrm{Na}_{2} \mathrm{O}\right]$ the crack front increasingly encounters $\mathrm{NBO}$ atoms with sodium (i.e. sodium acts as a network modifier) charge compensation type bonds (i.e. $\equiv(\mathrm{Si}$ or $\mathrm{B})-\mathrm{O} \cdot \mathrm{Na} \cdots \mathrm{Na} \cdot \mathrm{O}-(\mathrm{Si}$ or $\mathrm{B}) \equiv$, where $\equiv$ is the glass network) [65]. Hence, increasing $\left[\mathrm{Na}_{2} \mathrm{O}\right]$ favors water penetration and increases the slope. Celarie [84] specifically observed migration of sodium ions towards the free surface during crack tip propagation. The occurrence of this mechanism preferentially opens these weak paths aiding in the penetration of water, per Tomozawa's theory. Finally, Tomozawa found an increased resistance of the glass to SCC which he attributes to an enhanced plastic flow at the crack tip [85]. It is true that plastic flow at the crack tip will shift $K_{e}$ to higher $K_{I}$ values, but if it deters the velocity in SBN glasses, then the slope should be lower. Herein, it is higher.

The interpretation of the slope in the region I cannot be rationalized via the Wiederhorn's model. Tomozawa's theory maybe consistent with the huge variation in slope as a function of the sodium content. On the other hand, if the slope were impacted by plastic flow processes in this series of glasses, the slope should decrease rather it increases. The penetration of water molecules sets up a preferential weak path along sodium rich regions (and their corresponding NBO atoms). Moreover, the increase in $\left[\mathrm{Na}_{2} \mathrm{O}\right]$ increases the glasses reactivity with water. This in turn forms a weaker glass and due to the depolymerization of the glass the slope increases.

\subsection{Region I and the glass structure}

The SBN glass structure changes drastically with the amount of $\left[\mathrm{Na}_{2} \mathrm{O}\right]$ as discussed above (see Raman images Fig. 10). An interesting region I SCC phenomenon occurs when you consider the sodium role as a network compensator or a network modifier.

When sodium is predominantly acting as a network compensator on the boron network (i.e. SBN12 and SBN70), few NBO atoms exist in the glasses (Fig. 11). Thus, the glasses remain rather connected (DP around 1) and the slopes are rather similar (Fig. 8a).

When sodium predominantly acts as a network compensator on the boron network and a network modifier on the silica network (SBN63), a relatively small number of NBO atoms exist (Fig. 11). The example herein, SBN63, has a slight decrease in the slope. This glass is highly connected with the greatest number of ${ }^{[4]} \mathrm{B}$ units, but has about $25 \%$ of the silica

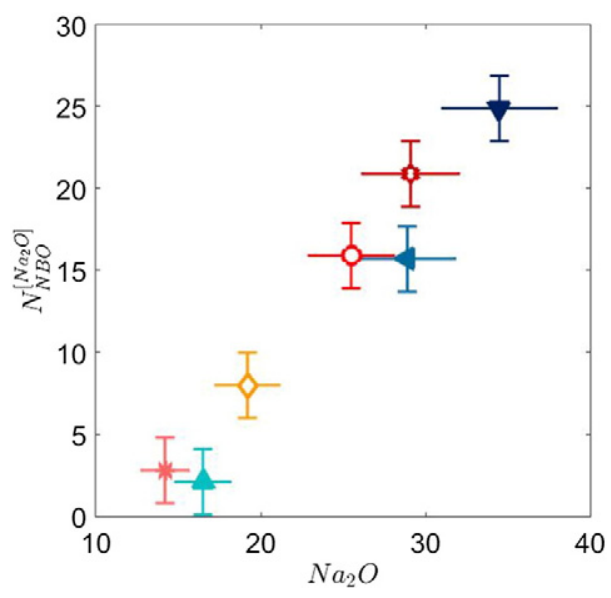

Fig. 11. Percent of $\left[\mathrm{Na}_{2} \mathrm{O}\right]$ leading to $\mathrm{NBO}$ (see reference [6]) calculated from NMR experiments, $N_{N B O}^{\left[\mathrm{Na}_{2} \mathrm{O}\right]}=\frac{1}{2} N_{N B O}$, versus [ $\left.\mathrm{Na}_{2} \mathrm{O}\right]$ in the glasses.

tetrahedrons with NBOs. The ${ }^{[4]} \mathrm{B}$ units affect the rigidity of network and decrease the floppiness of the NBO atoms, and the overall effect causes a slight decrease in the slope.

For the rest of the samples, the slope increases significantly with the amount of sodium. Sodium acts as a network modifier for both the Boron and Silica network in these samples. This causes depolymerization in samples and increases the "floppy modes" available to the glasses, allowing as seen above for the $K_{e}$ to increase. However, due to the preferential paths (channels/pockets) setup by the Sodium atoms $\mathrm{H}^{+} / \mathrm{H}_{2} \mathrm{O} / \mathrm{H}_{3} \mathrm{O}^{+}$is able to penetrate easier into the process zone, thus causing weak points. The fractures in these samples are not really the propagation of the crack front, but the merger of weak points in the glass. This idea is further enhanced by Fig. 9 which shows the number of $\mathrm{Si}-\mathrm{O}$ and $\mathrm{B}-\mathrm{O}$ bonds broken as the crack propagates to decrease significantly as $\left[\mathrm{Na}_{2} \mathrm{O}\right]$ increases. In other words, if the bonds are not in the wake of the crack, the crack front will not break them.

\section{Conclusion}

In summary, the work herein demonstrates that $\left[\mathrm{Na}_{2} \mathrm{O}\right]$ plays an important role on region 0 and I for the 7 Ternary SBN glasses examined herein. Increasing $\left[\mathrm{Na}_{2} \mathrm{O}\right]$ shifts $K_{e}$ to higher values. Region I provided an unexpected and unexplored response of the glass as a function of $\left[\mathrm{Na}_{2} \mathrm{O}\right]$ role in the glass. Increasing $\left[\mathrm{Na}_{2} \mathrm{O}\right]$ has a profound effect on the steepness of the SCC curve as the stress intensity factor increases. This effect is highly nonlinear: For $R_{S B N} \leqslant R_{d 1}=0.5+0.25 K_{S B N}$ (which for

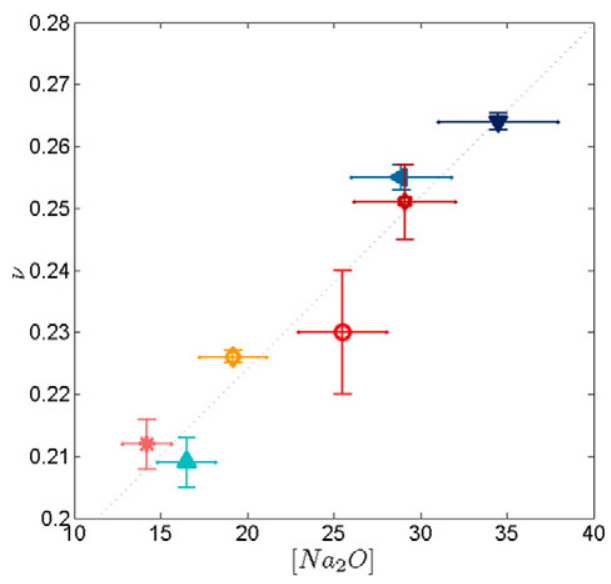

Fig. 12. The image presents results concerning the Poisson ratio $(\nu)$ dependence on $\left[\mathrm{Na}_{2} \mathrm{O}\right]$. 


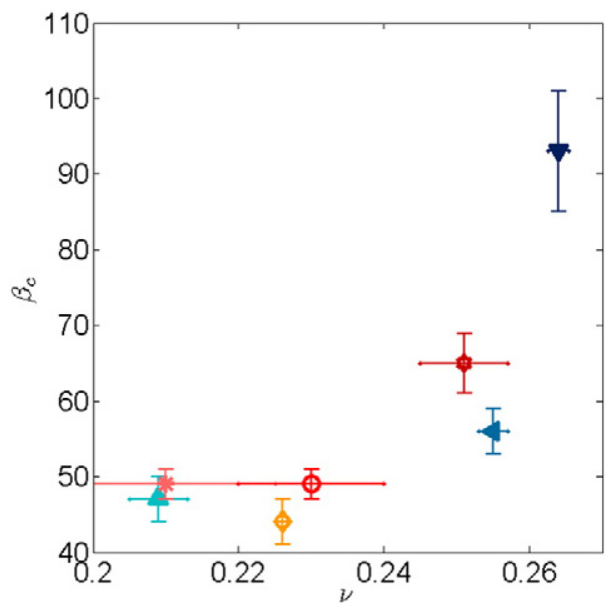

Fig. 13. The evolution of $\beta_{c}$ (using Wiederhorn's model $[1,48,49]$ ) with the Poisson ratio $(\nu)$.

the glasses considered herein corresponds to $\left[\mathrm{Na}_{2} \mathrm{O}\right] \leqslant 20 \%$ ), a slight decreasing trend is barely visible, but within the uncertainty, these values are constant. To understand if this is a true trend or just the spread of the data, a larger selection of samples are needed within this zone. On the other hand when $R_{S B N} \geq R_{d 1}=0.5+0.25 K_{S B N}$ (which for the glasses considered herein corresponds to $\left[\mathrm{Na}_{2} \mathrm{O}\right] \approx 20 \%$ ), the logarithmic slope $\beta_{c}=$ $d(\log v) / d K($ or $n=d(\log v) / d(\log K))$ dramatically increases with $\left[\mathrm{Na}_{2} \mathrm{O}\right]$. This cannot be understood by looking at the relative proportion of bonds. Rather the mesoscale (interconnects, rings, arrangement nonbridging oxygen atoms, and structure of the glass) dominates the behavior, and sodium's role as a network modifier (too both the silica and borate units) is of upmost importance on this mesoscale structure (its degree of depolymerisation) and subsequently on the selection of the SCC behavior. Quite surprisingly, the Poisson ratio $(\nu)$ fails to fully track this role. These series of findings should stimulate scientific investigations of the full Ternary diagram. Understanding the full Ternary diagram will aid in developing the best glass for specific uses.

\section{Acknowledgments}

The authors are grateful to T. Bernard for technical assistance and to T. Charpentier and M. Moskura who have provided the NMR results on SBN63 for this paper in order to complete the SBN. CEA, AREVA, Triangle de la Physique (RTRA) and Ile-de-France (C'Nano and ISC-PIF) have supported this research work.

\section{Appendix A. Estimate of humidity and temperature during SCC experiments}

Table A1

Table presents the typical temperatures in the isolation box during the period of the SCC experiments. An automated system recording relative humidity $(\mathrm{RH})$ and temperature was not available during the experiments. Thus, experimenters recorded measurements by hand.

\begin{tabular}{lll}
\hline & $\frac{\mathrm{T}}{\left.n^{\circ} \mathrm{C}\right)}$ & $\frac{\mathrm{RH}}{(\%)}$ \\
\hline Glass & $\left(28_{ \pm 3}\right)^{\mathrm{b}}$ & $\left(45_{ \pm 7}\right)^{\mathrm{b}}$ \\
SBN12 & $\left(31_{ \pm 4}\right)^{\mathrm{a}}$ & $\left(41_{ \pm 2}\right)^{\mathrm{a}}$ \\
SBN35 & $\left(34_{ \pm 3}\right)^{\mathrm{a}}$ & $\left(46_{ \pm 5}\right)^{\mathrm{a}}$ \\
SBN70 & $\left(30_{ \pm 4}\right)^{\mathrm{b}}$ & $\left(43_{ \pm 3}\right)^{\mathrm{b}}$ \\
SBN63 & $\left(28_{ \pm 3}\right)^{\mathrm{b}}$ & $\left(43_{ \pm 8}\right)^{\mathrm{b}}$ \\
SBN59 & $\left(28_{ \pm 3}\right)^{\mathrm{b}}$ & $\left(43_{ \pm 8}\right)^{\mathrm{b}}$ \\
SBN55 & $\left(27_{ \pm 3}\right)^{\mathrm{a}}$ & $\left(45_{ \pm 5}\right)^{\mathrm{a}}$ \\
\hline
\end{tabular}

a Corresponds to the average temperatures and $\mathrm{RH}$ recorded by the experimenter during the SCC experiments.

b Corresponds to average seasonal measurements as the experiments progressed continuously.

\section{References}

[1] S.M. Wiederhorn, Influence of water vapor on crack propagation in soda-lime glass, J. Am. Ceram. Soc. 50 (8) (1967) 407, http://dx.doi.org/10.1111/j.1151-2916.1967. tb15145.x.

[2] S. Wiederhorn, L. Bolz, Stress corrosion and static fatigue of glass, J. Am. Ceram. Soc. 53 (1970) 543-548, http://dx.doi.org/10.1111/j.1151-2916.1970.tb15962.x.

[3] M. Ciccotti, Stress-corrosion mechanisms in silicate glasses, J. Phys. D Appl. Phys. 42 (21) (2009) 214006

[4] S.M. Wiederhorn, R.L. Moses, B.L. Bean, Plastic deformation and the fracture surface energy of sodium chloride, J. Am. Ceram. Soc. 53 (1) (1970) 18-23, http://dx.doi. org/10.1111/j.1151-2916.1970.tb11991.x.

[5] M. Bertoldi, V.M. Sglavo, Influence of composition on fatigue behavior and threshold stress intensity factor of borosilicate glasses, J. Am. Ceram. Soc. 85 (10) (2002) 2499-2506, http://dx.doi.org/10.1111/j.1151-2916.2002.tb00487.x.

[6] M. Barlet, A. Kerrache, J.-M. Delaye, C.L. Rountree, $\mathrm{SiO}_{2}-\mathrm{Na}_{2} \mathrm{O}-\mathrm{B}_{2} \mathrm{O}_{3}$ density: a comparison of experiments, simulations, and theory, J. Non-Cryst. Solids 382 (2013) 32-44 (http://www.sciencedirect.com/science/article/pii/S0022309313004869).

[7] M. Barlet, J.-M. Delaye, T. Charpentier, M. Gennisson, D. Bonamy, T. Rouxel, C.L. Rountree, Hardness and toughness of sodium borosilicate glasses via Vicker's indentations, J. Non-Cryst. Solids 417-418 (2015) 66-79 (www.sciencedirect.com/science/article/pii/S0022309315000538).

[8] P. McMillan, A. Chlebik, Xiith international congress on glass the effect of hydroxyl ion content on the mechanical and other properties of soda-lime-silica glass, J. Non-Cryst. Solids 38 (1980) 509-514 (http://www.sciencedirect.com/science/article/pii/0022309380904706).

[9] M. Barlet, J.-M. Delaye, D. Bonamy, C.L. Rountree, Understanding the evolution of mechanical properties under irradiation in nuclear glasses via experiments, 13th International Conference on Fracture, Beijing, China, 2013 (www.gruppofrattura.it/ ocs/index.php/ICF/icf13/paper/download/11521/10900).

[10] M. Barlet, Evolution of mechanical properties of silicate glasses: impact of the chemical composition and effects of irradiation(Ph.D. thesis) Ecole Polytechnique, 2014

[11] M. Barlet, J.-M. Delaye, M. Gennisson, R. Caraballo, B. Boizot, B. Bonamy, C.L. Rountree, Influence of electronic irradiation on failure and hardness properties of pure silica glasses, Procedia Mater. Sci. 7 (2014) 286-293.

[12] W.J. Dell, P.J. Bray, S.Z. Xiao, ${ }^{11} \mathrm{~B}$ NMR-studies and structural modeling of $\mathrm{Na}_{2} \mathrm{O}-\mathrm{B}_{2} \mathrm{O}_{3}$ $\mathrm{SiO}_{2}$ glasses of high soda content, J. Non-Cryst. Solids 58 (1) (1983) 1-16.

[13] D. Feil, S. Feller, The density of sodium borosilicate glasses related to atomic arrangements, J. Non-Cryst. Solids 119 (1) (1990) 103-111.

[14] K. Budhwani, S. Feller, A density model for the lithium, sodium and potassium borosilicate glass systems, Phys. Chem. Glasses 36 (4) (1995) 183-190.

[15] H. Inoue, A. Masuno, Y. Watanabe, K. Suzuki, T. Iseda, Direct calculation of the physical properties of sodium borosilicate glass from its chemical composition using the concept of structural units, J. Am. Ceram. Soc. 95 (1) (2012) 211-216.

[16] C.L. Rountree, S. Prades, D. Bonamy, E. Bouchaud, R. Kalia, C. Guillot, A unified study of crack propagation in amorphous silica: using experiments and simulations, J. Alloys Compd. 434 (2007) 60-63.

[17] F. Celarie, S. Prades, D. Bonamy, A. Dickele, E. Bouchaud, C. Guillot, C. Marliere, Surface fracture of glassy materials as detected by real-time atomic force microscopy (AFM) experiments, Appl. Surf. Sci. 212 (2003) 92-96.

[18] C. Rountree, D. Bonamy, D. Dalmas, S. Prades, R. Kalia, C. Guillot, E. Bouchaud, Fracture in glass via molecular dynamics simulations and atomic force microscopy experiments, Phys. Chem. Glasses Eur. J. Glass Sci. Technol. B 51 (2010) 127-132.

[19] D. Bonamy, S. Prades, C.L. Rountree, L. Ponson, D. Dalmas, E. Bouchaud, K. RaviChandar, C. Guillot, Nanoscale damage during fracture in silica glass, Int. J. Fract. $140(1-4)$ (2006) 3-14.

[20] D. Bonamy, S. Prades, L. Ponson, D. Dalmas, C. Rountree, E. Bouchaud, C. Guillot, Experimental investigation of damage and fracture in glassy materials at the nanometre scale, Int. J. Mater. Prod. Technol. 26 (3-4) (2006) 339-353.

[21] G. Pallares, L. Ponson, A. Grimaldi, M. George, G. Prevot, M. Ciccotti, Crack opening profile in dcdc specimen, Int. J. Fract. 156 (1) (2009) 11-20.

[22] M. He, M. Turner, A.G. Evans, Analysis of the double cleavage drilled compression specimen for interface fracture energy measurements over a range of mode mixities, Acta Metall. Mater. 43 (9) (1995) 3453-3458 (http://www.sciencedirect. com/science/article/pii/095671519500036U).

[23] S. Prades, D. Bonamy, D. Dalmas, E. Bouchaud, C. Guillot, Nano-ductile crack propagation in glasses under stress corrosion: spatiotemporal evolution of damage in the vicinity of the crack tip, Int. J. Solids Struct. 42 (2) (2005) 637-645.

[24] B. Boizot, G. Petite, D. Ghaleb, B. Reynard, G. Calas, Structural evolution of simplified nuclear glasses under-irradiation: a Raman spectroscopy study, Mater. Res. Soc. Proc. 540 (1998) 401, http://dx.doi.org/10.1557/proc-540-401.

[25] D. Matson, S. Sharma, J. Philpotts, The structure of high-silica alkali-silicate glasses. A Raman spectroscopic investigation, J. Non-Cryst. Solids 58 (1983) 323-352.

[26] D. Manara, A. Grandjean, D.R. Neuville, Structure of borosilicate glasses and melts: a revision of the Yun, Bray and Dell model, J. Non-Cryst. Solids 355 (50-51) (2009) 2528-2531.

[27] F. Angeli, O. Villain, S. Schuller, S. Ispas, T. Charpentier, Insight into sodium silicate glass structural organization by multinuclear NMR combined with first-principles calculations, Geochim. Cosmochim. Acta 75 (9) (2011) 2453-2469.

[28] B. Boizot, S. Agnello, B. Reynard, R. Boscaino, G. Petite, Raman spectroscopy study of $\beta$-irradiated silica glass, J. Non-Cryst. Solids 325 (1-3) (2003) 22-28.

[29] G. Bureau, Comprehension structurale des effets d'auto-irradiation alpha dans les verres: couplage entre etudes spectroscopiques et modelisation atomistique(Ph.D. thesis) Universite Pierre et Marie Curie (Paris VI), 2008.

[30] P. McMillan, B. Piriou, R. Couty, A Raman study of pressure-densified vitreous silica, J. Chem. Phys. 81 (1984) 4234-4236. 
[31] T. Furukawa, K. Fox, W. White, Raman spectroscopic investigation of the structure of silicate glasses. iii. Raman intensities and structural units in sodium silicate glasses, J. Chem. Phys. 75 (1981) 3226-3237, http://dx.doi.org/10.1063/1.442472.

[32] J. de Bonfils, S. Peuget, G. Panczer, D. de Ligny, S. Henry, P.-Y. Noel, A. Chenet, B. Champagnon, Effect of chemical composition on borosilicate glass behavior under irradiation, J. Non-Cryst. Solids 356 (6-8) (2010) 388-393.

[33] H. Li, L. Su, D. Strachan, Raman spectroscopic study of gadolinium (iii) in sodiumaluminoborosilicate glasses, J. Non-Cryst. Solids 292 (2001) 167-176.

[34] B. Meera, A. Sood, N. Chandrabhas, J. Ramakrishna, Raman study of lead borate glasses, J. Non-Cryst. Solids 126 (3) (1990) 224-230.

[35] D. McKeown, F.L. Galeener, G. Brown Jr., Studies of Al coordination in silica-rich sodium aluminosilicate glasses and some related minerals, J. Non-Cryst. Solids 68 (1984) 361-378.

[36] W.L. Konijnendijk, The Structure of Borosilicate Glasses(Ph.D. thesis) Technological University Eindhoven, Eindhoven, Netherlands, 1975 (http://alexandria.tue.nl/ extra1/PRF2B/7706562.pdf).

[37] W. Konijnendijk, J. Stevels, The structure of borate glasses studied by Raman scattering, J. Non-Cryst. Solids 18 (1975) 307-331.

[38] W.L. Konijnendijk, Structural differences between borosilicate and aluminosilicate glasses studied by Raman scattering, Glastech. Ber. 48 (10) (1975) 216-218.

[39] B. Mysen, L. Finger, D. Virgo, F. Seifert, Curve-fitting of Raman-spectra of silicateglasses, Am. Mineral. 67 (1982) 686-695 (www.minsocam.org/ammin/AM67/ AM67_686.pdf).

[40] T. Yano, N. Kunimine, S. Shibata, M. Yamane, Structural investigation of sodium borate glasses and melts by Raman spectroscopy. ii. Conversion between $\mathrm{BO}_{4}$ and $\mathrm{BO}_{2} \mathrm{O}$-units at high temperature, J. Non-Cryst. Solids 321 (3) (2003) 147-156.

[41] R. Akagi, N. Ohtori, N. Umesaki, Raman spectra of $\mathrm{K}_{2} \mathrm{O}-\mathrm{B}_{2} \mathrm{O}_{3}$ glasses and melts, J. Non-Cryst. Solids 293-295 (2001) 471-476.

[42] L.-H. Kieu, Compréhension de l'origine de l'évolution sous irradiation de la ténacité des verres nucléaires(Ph.D. thesis) l'Ecole Polytechnique, 2011.

[43] L.-H. Kieu, J.-M. Delaye, L. Cormier, C. Stolz, Development of empirical potentials for sodium borosilicate glass systems, J. Non-Cryst. Solids 357 (18) (2011) 3313-3321 (http://www.sciencedirect.com/science/article/pii/S002230931100384X).

[44] S.W. de Leeuw, J.W. Perram, E.R. Smith, Simulation of electrostatic systems in periodic boundary conditions. i. Lattice sums and dielectric constants, Proc. R. Soc. Lond. A Math. Phys. Eng. Sci. 373 (1752) (1980) 27-56, http://dx.doi.org/10.1098/rspa.1980.0135.

[45] B. Guillot, N. Sator, A computer simulation study of natural silicate melts. Part i: low pressure properties, Geochim. Cosmochim. Acta 71 (5) (2007) 1249-1265 (http:// www.sciencedirect.com/science/article/pii/S0016703706021971).

[46] I.T. Todorov, W. Smith, K. Trachenko, M.T. Dove, Dl_poly_3: new dimensions in molecular dynamics simulations via massive parallelism, J. Mater. Chem. 16 (2006) 1911-1918 (http://pubs.rsc.org/en/content/articlehtml/2006/jm/b517931a).

[47] L.-H. Kieu, J.-M. Delaye, C. Stolz, Modeling the effect of composition and thermal quenching on the fracture behavior of borosilicate glass, J. Non-Cryst. Solids 358 (23) (2012) 3268-3279.

[48] S.M. Wiederhorn, E. Fuller, R. Thomson, Micromechanisms of crack-growth in ceramics and glasses in corrosive environments, Met. Sci. 14 (8-9) (1980) 450-458.

[49] S. Wiederhorn, S.W. Freiman, E.R. Fuller, C.J. Simmons, Effects of water and other dielectrics on crack-growth, J. Mater. Sci. 17 (12) (1982) 3460-3478, http://dx.doi. org/10.1007/BF00752191.

[50] R.J. Charles, W.B. Hillig, Union scientifique continentale du verre, Symposium on Mechanical Strength of Glass and Ways of Improving it., Florence, Italy 1961, pp. 511-527.

[51] T.A. Michalske, S.W. Freiman, A molecular interpretation of stress-corrosion in silica, Nature 295 (5849) (1982) 511-512.

[52] S.W. Freiman, Effects of chemical environments on slow crack growth in glasses and ceramics, J. Geophys. Res. Solid Earth 89 (B6) (1984) 4072-4076, http://dx.doi.org/ 10.1029/JB089iB06p04072.

[53] B.K. Atkinson, P.G. Meredith, Fracture mechanics of rock, Academic Press Geology Series, The Theory of Subcritical Crack Growth With Applications to Minerals and Rocks 1987, p. 119 (Ch., https://books.google.fr/books?hl=en\&lr=\&id=1dn$\mathrm{BAAAQBAJ} \& \mathrm{oi}=$ fnd $\& \mathrm{pg}=\mathrm{PA} 111 \& \mathrm{dq}=\mathrm{Si}-\mathrm{O}-$

$\mathrm{Si}+$ bond + to + be + the + limiting + factor $+\mathrm{in}+$ the + propagation + of + the + crac-


onepage $\& \mathrm{q}=\mathrm{si}-\mathrm{o} \& \mathrm{f}=$ false $)$.

[54] R.J. Charles, Static Fatigue of Glass. I, J. Appl. Phys. 29 (11) (1958) 1549-1553, http://dx.doi.org/10.1063/1.1722991.

[55] P.J. Bray, S.A. Feller, G.E. Jellison, Y.H. Yun, $B^{10}$ NMR-studies of the structure of borate glasses, J. Non-Cryst. Solids 38-39 (MAY) (1980) 93-98 (http://www.sciencedirect. com/science/article/pii/0022309380904007).

[56] Y.H. Yun, S.A. Feller, P.J. Bray, Correction and addendum to nuclear magneticresonance studies of the glasses in the system $\mathrm{Na}_{2} \mathrm{O}-\mathrm{B}_{2} \mathrm{O}_{3}-\mathrm{SiO}_{2}$, J. Non-Cryst. Solids 33 (2) (1979) 273-277.

[57] T. Rouxel, H. Ji, V. Keryvin, T. Hammouda, S. Yoshida, Poisson's ratio and the glass network topology - relevance to high pressure densification and indentation behavior, Adv. Mater. Res. 39-40 (2008) 137-146.
[58] E. Gehrke, C. Ullner, M. Hahnert, Fatigue limit and crack arrest in alkali-containing silicate glasses, J. Mater. Sci. 26 (20) (1991) 5445-5455, http://dx.doi.org/10. 1007/BF02403942.

[59] B. Lawn, Fracture of Brittle Solids, second ed. Cambridge University Press, 1993.

[60] T. Fett, J. Guin, S. Wiederhorn, Stresses in ion-exchange layers of soda-lime-silicate glass, Fatigue Fract. Eng. Mater. Struct. 28 (6) (2005) 507-514.

[61] E. Gehrke, C. Ullner, M. Hahnert, Effect of corrosive media on crack-growth of mode glasses and commercial silicate-glasses, Glastech. Ber. Glass Sci. Technol. 63 (9) (1990) 255-265

[62] S.M. Wiederhorn, Prevention of failure in glass by proof-testing, J. Am. Ceram. Soc. 56 (4) (1973) 227-228

[63] M. Tomozawa, D.J. Cherniak, P.J. Lezzi, Hydrogen-to-alkali ratio in hydrated alkal aluminosilicate glass surfaces, J. Non-Cryst. Solids 358 (24) (2012) 3546-3550.

[64] G. Geneste, F. Bouyer, S. Gin, Hydrogen-sodium interdiffusion in borosilicate glasses investigated from first principles, J. Non-Cryst. Solids 352 (2006) 3147-3152.

[65] L.-H. Kieu, J.-M. Delaye, C. Stolz, Modeling Radiation Effects on the Fracture Process in Simplified Nuclear Glass, Advances in Fracture and Damage Mechanics X, 488489, 2011, pp. 154-157, http://dx.doi.org/10.4028/www.scientific.net/kem.488489.154.

[66] C.L. Rountree, D. Vandembroucq, M. Talamali, E. Bouchaud, S. Roux, Plasticityinduced structural anisotropy of silica glass, Phys. Rev. Lett. 102 (2009) 195501 http://dx.doi.org/10.1103/PhysRevLett.102.195501.

[67] M.M. Smedskjaer, M. Bauchy, Sub-critical crack growth in silicate glasses: role of network topology, Appl. Phys. Lett. 107 (14) (2015) 141901, http://dx.doi.org/10. 1063/1.4932377.

[68] Y. Vaills, T. Qu, M. Micoulaut, F. Chaimbault, P. Boolchand, Direct evidence of rigidity loss and self-organization in silicate glasses, J. Phys. Condens. Matter 17 (32) (2005) 4889 (http://stacks.iop.org/0953-8984/17/i=32/a=003).

[69] B. Wang, Y. Yu, M. Wang, J.C. Mauro, M. Bauchy, Nanoductility in silicate glasses is driven by topological heterogeneity, Phys. Rev. B 93 (2016) 064202, http://dx.doi. org/10.1103/PhysRevB.93.064202.

[70] M. Micoulaut, Constrained interactions, rigidity, adaptative networks, and their role for the description of silicates, Am. Mineral. 93 (2008) 1732-1748 (http://www. minsocam.org/msa/ammin/toc/Abstracts/2008_Abstracts/ND08_Abstracts/ Micoulaut_p1732_08.pdf)

[71] M.M. Smedskjaer, Topological model for boroaluminosilicate glass hardness, Front Mater. 1 (2014) 1, http://dx.doi.org/10.3389/fmats.2014.00023.

[72] M.M. Smedskjaer, J.C. Mauro, R.E. Youngman, C.L. Hogue, M. Potuzak, Y. Yue, Topological principles of borosilicate glass chemistry, J. Phys. Chem. B 115 (44) (2011) 12930-12946, http://dx.doi.org/10.1021/jp208796b.

[73] A. Meyer, J. Horbach, W. Kob, F. Kargl, H. Schober, Channel formation and intermediate range order in sodium silicate melts and glasses, Phys. Rev. Lett. 93 (2004) 027801, http://dx.doi.org/10.1103/PhysRevLett.93.027801.

[74] R.A. Golombeck, Investigations of Adsorption Sites on Oxide Surfaces Using SolidState NMR and tpd-igc(Ph.D. thesis) Pennsylvania State University, 2008.

[75] D. Dalmas, C. Guerra, J. Scheibert, D. Bonamy, Damage mechanisms in the dynamic fracture of nominally brittle polymers, Int. J. Fract. 184 (1-2) (2013) 93-111.

[76] A. Grandjean, M. Malki, C. Simonnet, Effect of composition on ionic transport in $\mathrm{SiO}_{2}-\mathrm{B}_{2} \mathrm{O}_{3}-\mathrm{Na}_{2} \mathrm{O}$ glasses, J. Non-Cryst. Solids 352 (26-27) (2006) 2731-2736.

[77] G.N. Greaves, A.L. Greer, R.S. Lakes, T. Rouxel, Poisson's ratio and modern materials, Nat. Mater. 10 (11) (2011) 823-837.

[78] P. Sellappan, T. Rouxel, F. Celarie, E. Becker, P. Houizot, R. Conradt, Composition dependence of indentation deformation and indentation cracking in glass, Acta Mater. 61 (2013) 5949-5965.

[79] S. Glasstone, K. Laidler, H. Eyring, The theory of rate processes: the kinetics of chemical reactions, viscosity, diffusion and electrochemical phenomena, International Chemical Series, McGraw-Hill Book Company, Incorporated, 1941 (https://books. google.fr/books?id=zb2GAAAAIAAJ).

[80] R.E. Mould, Strength and static fatigue of abraded glass under controlled ambient conditions. 4. Effect of surrounding medium, J. Am. Ceram. Soc. 44 (10) (1961) 481-491.

[81] J. Guin, S. Wiederhorn, Crack growth threshold in soda lime silicate glass: role of hold-time, J. Non-Cryst. Solids 316 (2003) 12-20.

[82] R. Gy, Physical aspects of fracture, Stress Corrosion of Glass, Springer, Netherlands, Dordrecht 2001, pp. 305-320, http://dx.doi.org/10.1007/978-94-010-0656-9_22 (Ch.).

[83] M. Tomozawa, Fracture of glasses, Annu. Rev. Mater. Res. 26 (1996) 43-74.

[84] F. Celarie, M. Ciccotti, C. Marliere, Stress-enhanced ion diffusion at the vicinity of a crack tip as evidenced by atomic force microscopy in silicate glasses, J. Non-Cryst. Solids 353 (1) (2007) 51-68.

[85] A. Koike, M. Tomozawa, Size effect on surface structural relaxation kinetics of silica glass sample, J. Non-Cryst. Solids 352 (36-37) (2006) 3787-3793 (http://www. sciencedirect.com/science/article/pii/S0022309306009860).

[86] D. Maugis, Review: subcritical crack growth, surface energy, fracture toughness, stick-slip and embrittlement, J. Mater. Sci. 20 (1985) 3041-3073. 